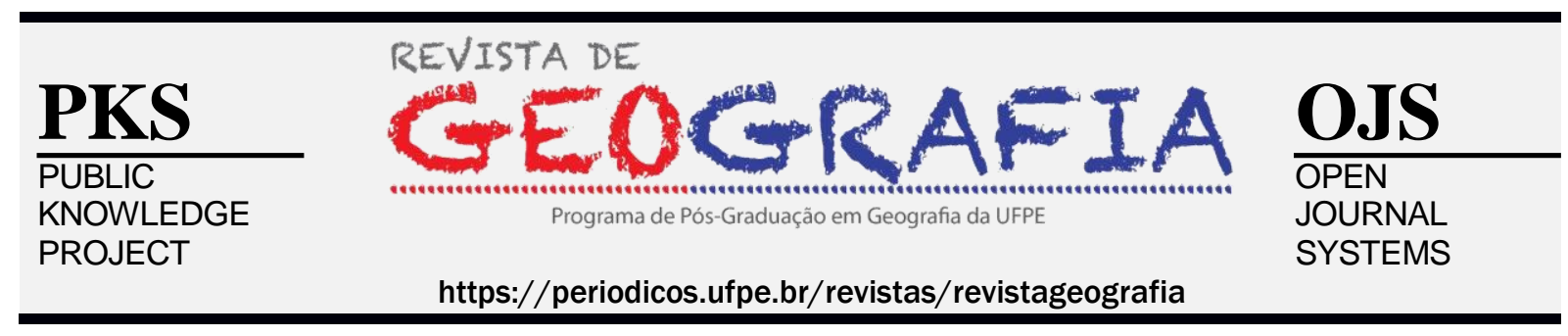

\title{
LOTEAMENTOS URBANOS E A RENDA DA TERRA EM COLATINA-ES
}

\author{
Leandro Camatta de Assis ${ }^{1}$, Vivian Albani ${ }^{2}$, Izabela Dolores Cebin Bassani ${ }^{3}$, Rafael \\ Santos da Luz Monteiro ${ }^{4}$
}

${ }^{1}$ Docente do Instituto Federal do Espírito Santo. E-mail: leandrocamatta@gmail.com

${ }^{2}$ Docente do Instituto Federal do Espírito Santo. E-mail: vivianalbani@gmail.com

${ }^{3}$ Mestre em Geografia pela Universidade Federal do Espírito Santo. E-mail: izabela_bassani@hotmail.com

${ }^{4}$ Mestre em Geografia pela Universidade Federal do Espírito Santo. E-mail: correiodorafael@hotmail.com

Artigo recebido em 29/11/2019 e aceito em 11/03/2020

\begin{abstract}
RESUMO
A compreensão das práticas dos agentes de produção do espaço urbano no Brasil, em especial, do setor imobiliário, é elemento essencial para o entendimento dos processos de expansão urbana e segregação socioespacial. $\mathrm{O}$ crescimento urbano horizontal se apresenta, como qualquer outra atividade produtiva que lida com a terra, como caminho encontrado para o capital adquirir lucros extraordinários. A discussão sobre a renda fundiária, mais especificamente da renda absoluta e de monopólio em Marx, é o ponto de partida teórico para este debate. A pesquisa empírica aborda os instrumentos de diferenciação e apropriação utilizados pelos promotores imobiliários nos loteamentos construídos na cidade de Colatina, estado do Espírito Santo, no período de 2005 a 2016. Por fim, a partir da premissa de que a cidade é produzida seguindo os interesses do capital, este se utiliza de estratégias de apropriação de condições espaciais de localização da cidade e da natureza para produzir lotes urbanos com preços de monopólio.
\end{abstract}

Palavras-chave: Renda da terra; Produção imobiliária; Loteamentos urbanos.

\section{URBAN ALLOTMENT AND LAND INCOME IN COLATINA-ES}

\begin{abstract}
The understanding of the practices of urban space production agents in Brazil, especially the real estate sector, is an essential element for understanding the processes of urban expansion and socio-spatial segregation. Horizontal urban growth, like any other productive activity that deals with the land, presents itself as a way of finding extraordinary profits. The discussion of land rent, more specifically of absolute rent and monopoly in Marx, is the theoretical starting point for this debate. The empirical research deals with the instruments of differentiation and appropriation used by real estate developers in the lots built in the city of Colatina, state of Espírito Santo, from 2005 to 2016. Finally, based on the premise that the city is produced following the interests of the capital, this one uses strategies of appropriation of the spatial conditions of localization of the city and the nature to produce urban batches with prices of monopoly.
\end{abstract}

Keywords: Land income. Real state production. Urban allotment. 


\section{INTRODUÇÃO}

A produção do espaço urbano através da construção de novos loteamentos provoca o crescimento horizontal das cidades e indica, no processo de produção da mercadoria lote urbano, a renda da terra como elemento essencial para ser estudado. O monopólio da propriedade fundiária e suas estratégias de apropriação de renda geram vazios e dispersão urbana que, por sua vez, devem ser analisados para a compreensão do processo de produção das cidades. A extração de renda a partir da propriedade privada da terra, como elemento promotor do aumento de áreas urbanizadas e que move as atividades produtivas criadoras de novos espaços urbanos, é a questão central deste artigo.

O crescimento urbano que avança sobre áreas rurais tende a transformar profundamente o ambiente natural e as relações intra-urbanas existentes. As áreas com características rurais, notada fragilidade ambiental e um incipiente processo produtivo agropecuário, cedem com maior facilidade territórios para um crescimento urbano acelerado. Tal processo é, grosso modo, marcado pela falta de planejamento adequado por parte do Estado, que vise a promoção de ocupação de áreas mais centrais e a densificação urbana em edificações ociosas nas cidades.

Para evidenciar características específicas, considera-se que o crescimento das cidades pode ocorrer de duas formas distintas: a primeira é através da verticalização das edificações e do aumento da densidade; a segunda forma dá-se por meio do crescimento da malha urbana da cidade, o chamado crescimento horizontal, que ocorre, principalmente, através de loteamentos formais ou de ocupações irregulares.

É a segunda forma de crescimento mencionada, através da expansão da malha urbana, que interessa nesta pesquisa. A compreensão dos processos de construção dos loteamentos urbanos e sua relação com planejamento urbano é fundamental para o desenvolvimento das cidades. Esse fenômeno espacial é observado na cidade de Colatina, município do estado do Espírito Santo.

A cidade de Colatina apresenta um crescimento horizontal acelerado a partir de 2005, o que aumentou a área urbanizada em aproximadamente 37\%, até o ano de 2018. O ano de 2005 foi definido para a pesquisa, pois foi o período de aprovação do projeto para a construção do primeiro loteamento na região do bairro Fazenda Vitali, que será investigado neste artigo. 
Colatina é um município localizado na região Centro-Oeste do estado do Espírito Santo e é cortado pelo rio Doce, pela estrada de ferro Vitória-Minas, pelas rodovias BR-259 e ES080, conforme mostra a figura 1. Em relação à economia do município convém ressaltar o destaque dos setores de comércio e serviços, além da centralidade regional adquirida ao longo do século XX, conforme relata Campos Junior (2004).

Figura 1 - Localização e infraestrutura de transporte do município de Colatina.

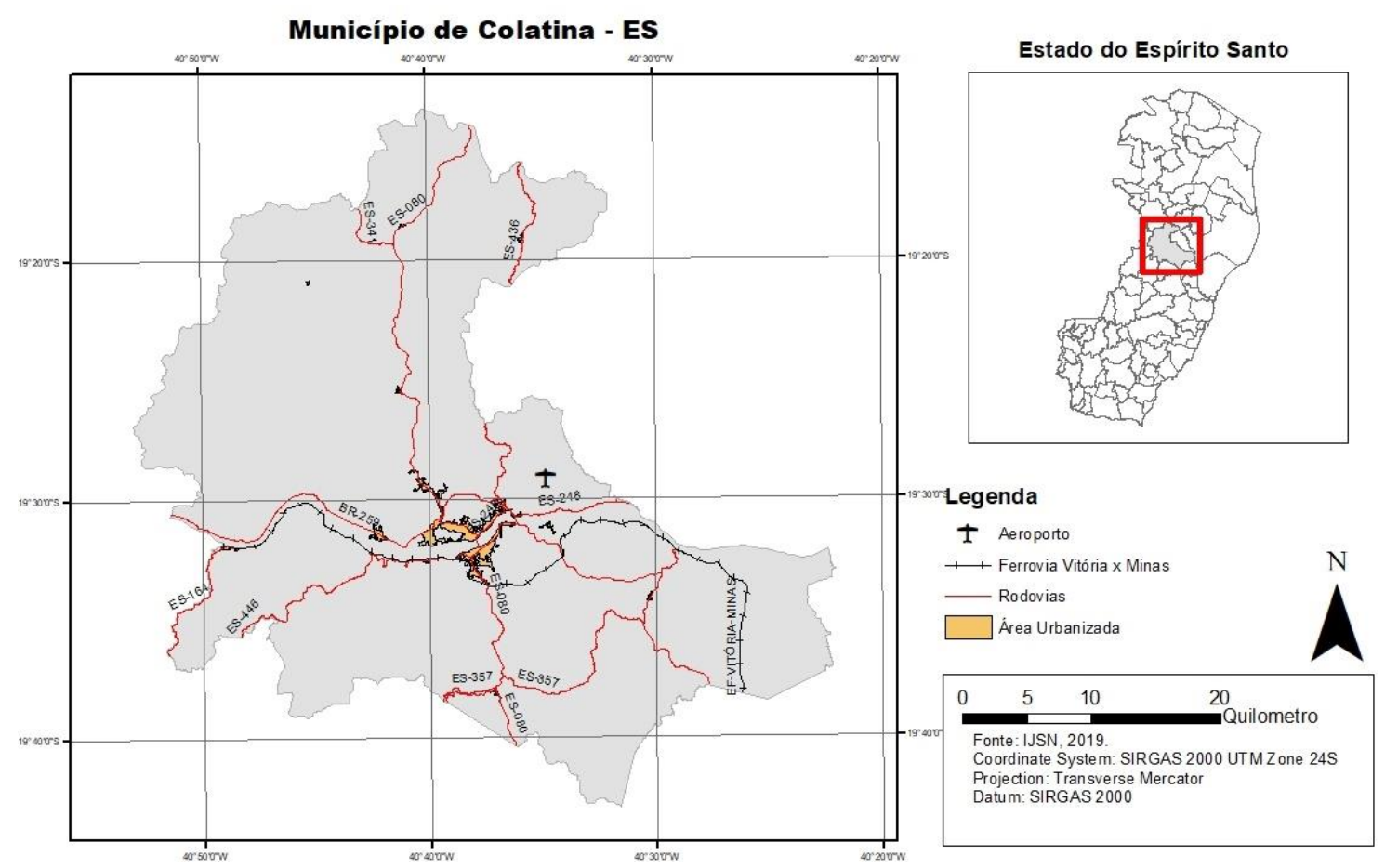

Fonte: Instituto Jones dos Santos Neves (2011). Elaborada pelos autores.

O porquê de as cidades crescerem de maneira dispersa, gerando vazios expandindo seus limites, é questão importante a ser estudada, uma vez que se relaciona diretamente com a forma de produção dos loteamentos. A análise do processo de apropriação da renda a partir da propriedade terra, mais especificamente, no processo de transformação da terra rural em terra urbana (lote), será utilizada como ferramenta teórica auxiliar para a compreensão dos fenômenos aqui investigados. Além disso, é necessário ressaltar na análise a superação do entendimento tradicional de centro x periferia, onde a área periférica concentra os moradores excluídos da cidade formal e o centro é o local da elite possuidora de bens e meios para usufruir da cidade. 
Dessa forma, é importante compreender a terra como capital e analisar o momento de sua transformação em terra urbana, com seus valores e usos intrínsecos.

Dessa forma, o objetivo desta pesquisa é analisar as características de loteamentos urbanos aprovados de 2005 a 2018 pela Prefeitura Municipal de Colatina e, em especial, os mecanismos de diferenciação do produto para valorização urbana do empreendimento, de modo a revelar as estratégias de apropriação do desenvolvimento da cidade e de aspectos da natureza. Assim sendo, ao se identificar os meios que garantem um ganho extra ao promotor imobiliário, torna-se possível compreender como o desenvolvimento urbano da cidade é apropriado pelo mercado imobiliário para estabelecer preços de monopólio. Dessa forma, a hipótese repousa na ideia de que a extração de renda da terra, sob a forma de loteamentos urbanos, é componente essencial para a produção do espaço pelo setor imobiliário.

\section{A RENDA DA TERRA NO PROCESSO PRODUTIVO DE LOTES URBANOS}

As questões que envolvem a propriedade da terra no processo de produção do espaço remetem para uma observação mais minuciosa da divisão da mais-valia entre lucro e renda. A propriedade privada do solo permite ao seu possuidor requerer uma parte do excedente produzido na construção dos edifícios, sob a forma de renda. Mais que isso, a propriedade da terra como uma mercadoria, mesmo que não resultante de produto do trabalho humano, tem seu preço estabelecido por uma expectativa de produção de um edifício nela, e ele, o preço, é, portanto, renda capitalizada. Para Pereira (1988), o valor suposto da propriedade da terra é determinado pela pressuposição de um valor de troca estabelecido na relação com outras mercadorias. Ainda segundo Pereira (1998, p.9) “O próprio preço com que a propriedade da terra é remunerada resulta da capitalização da renda gerada pela mercadoria cuja produção nela se localiza".

A terra, segundo Harvey (s.d.), é também meio de reprodução para o capital enquanto condição básica de vida para a população. Logo, o ambiente construído é o local onde se concentram os conflitos, pois o poder monopolístico oriundo dos arranjos da propriedade privada cria a possibilidade de se apropriar da renda e confere aos proprietários de terras o controle da oferta do espaço urbano e da força de trabalho ali disponível.

Ainda de acordo com Harvey (s.d.), parte fundamental para a determinação do preço de uma residência é composta pelas condições que a rodeia. Pode-se afirmar, assim, que não 
apenas os promotores imobiliários, mas também os proprietários de imóveis estão interessados na criação de uma "boa vizinhança" para a manutenção do potencial de transformação do valor de uso de sua residência em valor de troca.

São diversas as formas encontradas para que, na sociedade contemporânea, grandes glebas de terra pertençam a uma minoria de proprietários que, por monopolizar qualidades, ou forças naturais, asseguram um lucro extra. Sobre isso, Marx (2017) afirma que:

Essa renda se caracteriza,(...) pelo predomínio do preço monopólico em muitos casos, principalmente na exploração mais desavergonhada da miséria (pois a miséria é, para os locadores de imóveis, uma fonte mais lucrativa que as minas de Potosí já foram para a Espanha), e pelo poder descomunal que essa propriedade fundiária proporciona quando, reunida nas mesmas mãos com o capital industrial, praticamente habilita este último a excluir da Terra, enquanto sua moradia, os trabalhadores em luta pelo salário. (MARX, 2017, p. 833 e 834$)$

A renda da terra, segundo Marx, apud Bottomore (2001), deve então ser entendida pela análise da relação social entre capital e terra, e, para aquelas indústrias que dependem particularmente da terra como meio de produção, a propriedade fundiária possui efeito sobre seu desenvolvimento.

Ressalta-se aqui que, para Marx (2017), a propriedade fundiária é fonte de rendimento, no sentido de que o capital atrai para o capitalista uma parte da mais-valia, e o monopólio da terra atrai para seu proprietário outra parte, sob o nome de renda. Harvey (1990) contribui na compreensão sobre a renda ao afirmar que esta é um pagamento feito aos seus proprietários pelo simples direito de utilizá-la.

Ao estudar os preços agrícolas e a renda fundiária, Marx (2017) considera que é devido ao monopólio da propriedade fundiária que o excedente de valor dos produtos agrícolas sobre seu preço de produção se torna fator determinante de seu preço geral de mercado. Ainda segundo Marx (2017), o preço de produtos agrícolas situados acima do preço de produção, em função da existência da propriedade fundiária, depende da situação geral do mercado e que a mais-valia gerada na agricultura, e acima do lucro médio dado, se transforma em renda absoluta.

De todo modo, essa renda absoluta, derivada do excedente do valor sobre o preço de produção, é apenas parte do mais-valor agrícola, a transformação desse mais-valor em renda, a captação dele pelo proprietário da terra; exatamente como renda diferencial se origina da transformação de lucro extra em renda, da captação deste último pela propriedade da terra, com um preço geral de produção regulador. Essas duas 
formas de renda são as únicas normais. Fora delas, a renda só pode basearse num preço monopólico propriamente dito, que não é determinado nem pelo preço de produção nem pelo valor das mercadorias, mas pela necessidade e pela solvência dos compradores. (MARX, 2017, p.824, grifo dos autores).

É importante transpor a discussão sobre produtos agrícolas e renda para a construção imobiliária. Pereira (1988) contribui para o debate ao reforçar o papel da renda da terra, e o fato de que esta é produto do trabalho, mas também pode estar vinculada a processos de especulação fundiária, portanto não ligado diretamente a atividade produtiva. E que, por essa razão, ela pode estabelecer um preço de produção ou ainda um preço regulador de mercado. Salientamos que o grande e/ou pequeno estoque de imóveis disponível no mercado serve também como instrumento de controle e regulação dos preços.

Marx (2017) aponta ainda que, a renda de monopólio pode ser considerada um lucro extraordinário do preço de monopólio, especialmente no caso dos terrenos para construção. Para explicar a renda de monopólio Marx (2017) se utiliza do exemplo dos vinhos:

Um vinhedo que produz um vinho de qualidade excepcional, que de fato só pode ser produzido em quantidade relativamente pequena, tem um preço monopólico. Devido a esse preço monopólico, cujo excedente acima do valor do produto é determinado exclusivamente pela riqueza e pela paixão de eminentes bebedores de vinho, o viticultor consegue gerar um considerável lucro extra. Esse lucro extra, que aqui emana de um preço monopólico, transforma-se em renda e, desse modo, cai em poder do proprietário fundiário, devido a seu título sobre essa parcela do globo terrestre dotada de atributos especiais. Aqui, portanto, o preço monopólico cria a renda. (MARX, 2017, p. 835)

Portanto, a busca por características singulares e qualidades excepcionais, como diferenciação de certas mercadorias, possibilita a obtenção de lucros extraordinários. Tal estratégia será analisada como elemento componente do processo de produção dos loteamentos urbanos.

Ressalta-se aqui que, na moderna propriedade da terra existe a renda absoluta, pelo simples fato de existir o monopólio de utilização do mesmo. Isso dá ao seu proprietário o direito de exigir um pagamento pelo seu uso. Existe ainda, para os lotes urbanos, a possibilidade de uma renda de monopólio, que pode apresentar-se como uma qualidade exclusiva da localização do mesmo, segundo diversos critérios, e que é perseguida por capitalistas e proprietários fundiários. 


\section{ESTRATÉGIAS PARA DIFERENCIAÇÃO DOS LOTEAMENTOS URBANOS EM COLATINA - ES}

A expansão da produção imobiliária observada nos últimos anos apresentou formas de produção da cidade revestidas de "novas" qualidades para alcançar os objetivos do mercado. Essas qualidades se tornam características de uma mercadoria com um alto grau de fetiche, a casa.

Para visualizar tais estratégias, apresentar-se-á aqui a construção de lotes urbanos em Colatina, Espírito Santo, em sua produção recente, mais precisamente, a partir de 2005. Nesse período, a cidade de Colatina aumentou sua área urbanizada em 37\% e foram aprovados 54 projetos de loteamentos, com picos de aprovação nos anos de 2012 e 2016, conforme pode ser observado no gráfico 1 .

Gráfico 1- Loteamentos aprovados em Colatina

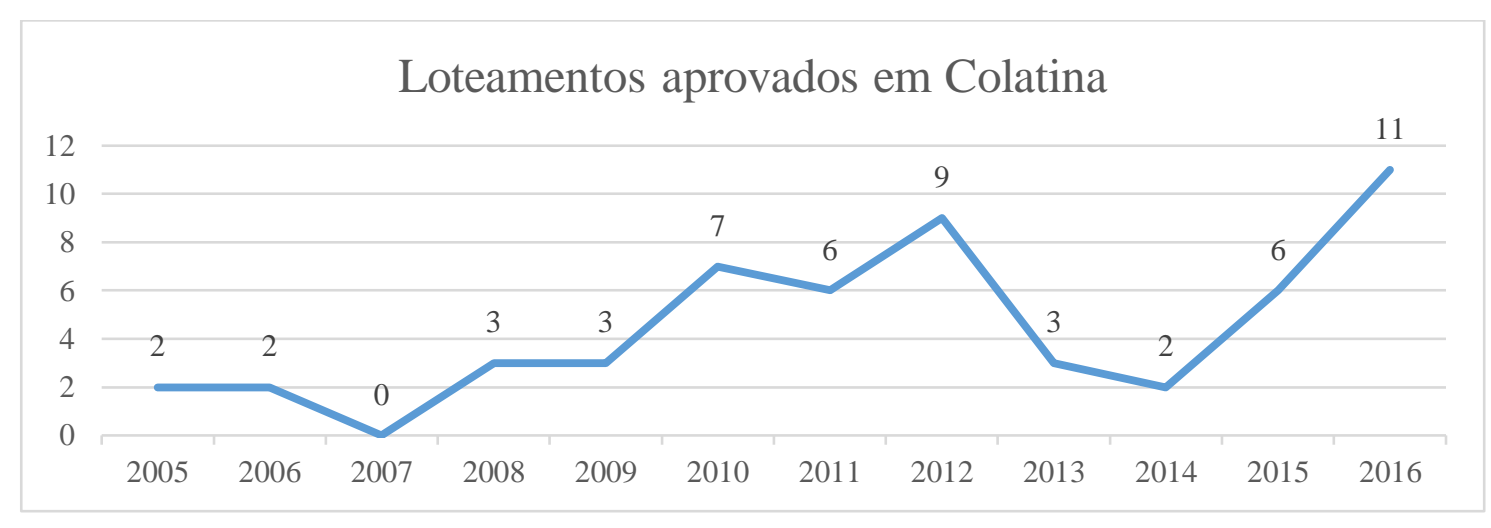

Fonte: Prefeitura Municipal Colatina (2016). Elaborado pelos autores.

Para o recorte espacial das estratégias de diferenciação utilizadas, foi estudada uma região específica da cidade, a que compreende o bairro Fazenda Vitali (figura 2) e parte de bairros vizinhos, que são formados por 10 loteamentos construídos a partir de 2005. Na análise destes loteamentos, verificou-se que a região possui área aproximada de 121 hectares, o que corresponde a cerca de $10 \%$ da mancha urbana da cidade de Colatina. Esse conjunto de loteamentos foi utilizado como referência para se compreender as estratégias de diferenciação dos produtos "lotes urbanos". 
Figura 2 - Localização do bairro Fazenda Vitali, em Colatina, com a demarcação dos loteamentos que lhe deram origem e suas respectivas datas de aprovação.

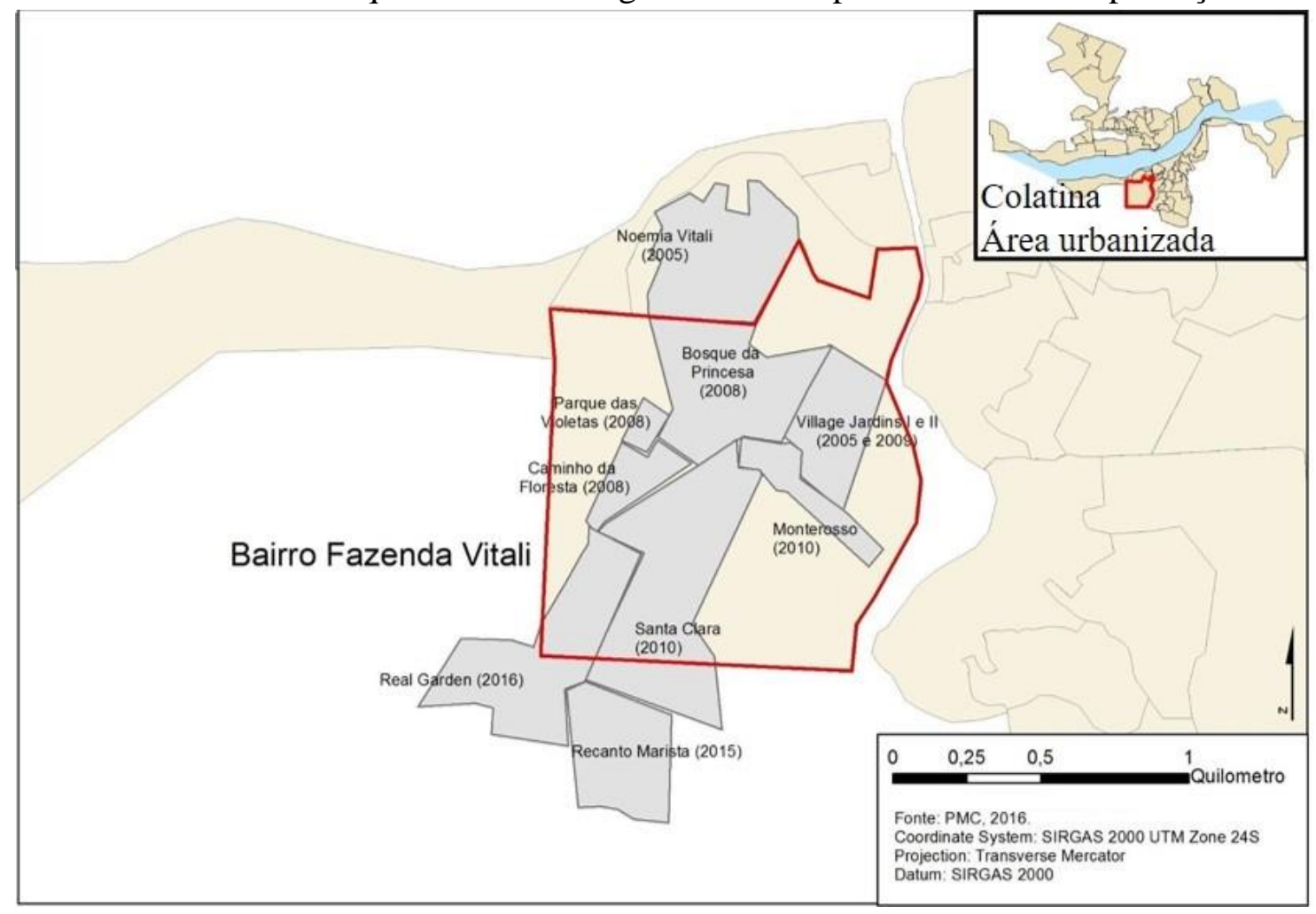

Fonte: Prefeitura Municipal de Colatina (2016). Adaptada pelos autores.

A consolidação dos primeiros loteamentos construídos foi uma das estratégias utilizadas para aumentar os lucros. Ao se apropriar de ganhos gerados por uma construção coletiva de cidade, os lotes urbanos se revestiam de características subjetivas e fetichizadas, como o "bairro nobre" da cidade. Tal título foi e é utilizado como estratégia de marketing para as vendas de novos produtos.

Convém ressaltar que dos dez loteamentos que compõem o universo de estudo, cinco deles pertencem a uma mesma empresa. Além disso, dois loteamentos possuem condomínios fechados de casas, sendo que, em um desses, foram comercializados os lotes para a construção e no outro foram vendidas as casas já construídas e com toda infraestrutura de área de lazer comum pronta.

Quando observamos a variação da média do preço dos lotes em Colatina (gráfico 02) percebemos que no período de aquecimento do mercado imobiliário no município (2006-2008) 
o valor apresenta maior percentual de crescimento, chegando a quase $40 \%$ em relação aos anos anteriores. Com a queda nas vendas e produção resultantes de uma instabilidade econômica nacional e também regional (2013-2014) a variação dos preços foi bem menor. Em 2015-2016 o mercado imobiliário local foi aquecido novamente com a chegada de novos empreendimentos demarcando uma nova fase de valorização dos terrenos.

Gráfico 2- Média do Preço do $\mathrm{m}^{2}$ dos lotes em Colatina

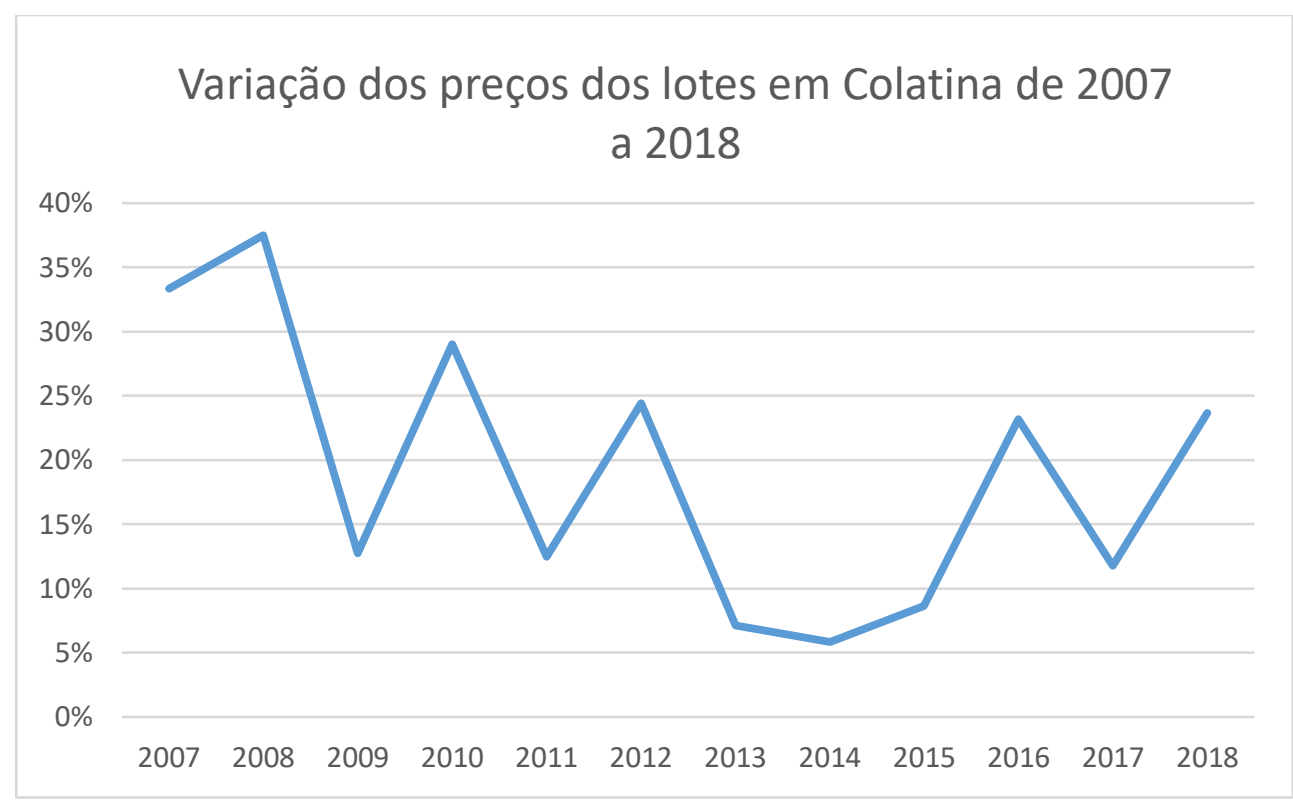

Fonte: Levantamento de dados dos autores com base nos sites das construtoras e corretoras de imóveis.

Para analisar o processo de produção de loteamentos na região mencionada é importante investigar a atividade prévia existente. A agricultura do município está fortemente marcada por dois fatores, quais sejam: a pequena propriedade familiar e a dependência em relação ao café. Seu desenvolvimento foi potencializado pela fertilidade natural do solo, uma vez que as matas nativas, abundantes no passado, davam lugar à cultura cafeeira e posteriormente a pecuária, atendendo ao ciclo mata-café-pastagens. Um breve inventário da região em análise permiti-nos verificar que a atividade produtiva que tais terras possuíam era, basicamente, a pecuária, que resistia de maneira arcaica e pouco produtiva na região que foi loteada - assim como grande parte das terras na região periurbana de Colatina, após o programa de erradicação dos cafezais na década de 60 em todo o estado do Espírito Santo. 
A antiga Fazenda Vitali, que deu origem aos loteamentos em análise e também ao nome do bairro, abrangia grande porção de terra e foi importante economicamente para a cidade e região, principalmente durante as primeiras décadas do século XX.

No que tange às estratégias de diferenciação dos lotes urbanos nos empreendimentos em análise, apresentadas pelos promotores imobiliários no momento da venda, verifica-se uma tática comum: a utilização de vantagens locacionais urbanas e naturais. Da instrumentalização da terra com artifícios urbanos, observa-se com frequência a utilização de estratégias de venda dos fatores de proximidade com as regiões de oferta de comércio e serviços da cidade, em especial, ao centro da cidade de Colatina. Além disso, equipamentos urbanos, como hospitais e escolas, são utilizados como atributos do espaço a ser comercializado, conforme mostra a figura 3.

Figura 3 - Imagem de divulgação de loteamento na região onde é valorizada a proximidade com os equipamentos urbanos da cidade.

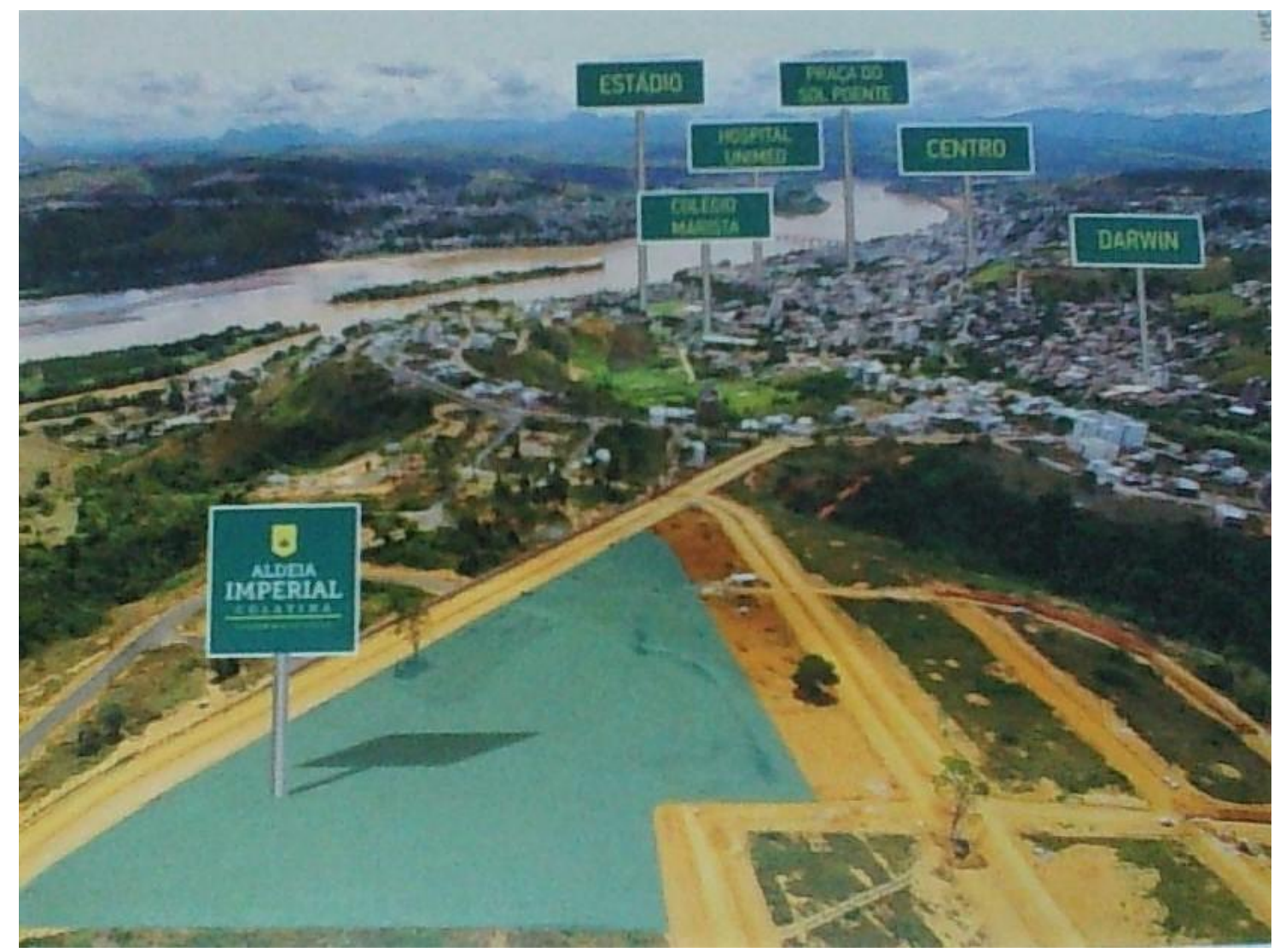

Fonte: Folder publicitário do empreendimento. Morar Construtora e Incorporadora, 2017. 
David Harvey (2014) afirma que mesmo os espaços públicos podem ser capitalizados, ou ainda projetados, para uma utilização capitalizada do mesmo e da valorização do espaço urbano.

Os sistemas de infraestrutura de água, esgoto, energia, drenagem e pavimentação de vias são ressaltados como qualidades extraordinárias oferecidas pelos novos lotes urbanos. No entanto, a infraestrutura de água, esgoto, energia, drenagem e pavimentação, assim como áreas destinadas a equipamentos urbanos e comunitários, que implica a obrigação do responsável pela execução do empreendimento (Lei Municipal n 4.227/1996), são convertidas em vantagens excepcionais da mercadoria em destaque. Conclui-se então que, quando grande parte da cidade não possui infraestrutura ou sofre com problemas frequentes de alagamento, exemplo de Colatina, a mínima condição urbana é tida como vantagem extraordinária.

Das vantagens naturais apropriadas pelo capital com o objetivo de aumentar lucros sobre as mercadorias em questão, aquelas que mais chamam a atenção, e que se repetem com frequência, são as que associam ao produto uma proximidade com a natureza e perfil “sustentável” do empreendimento (figura 4).

Figura 4 - Folder publicitário valorizando a sustentabilidade. Detalhe para a valorização do bairro com o rótulo de "o mais nobre da cidade".

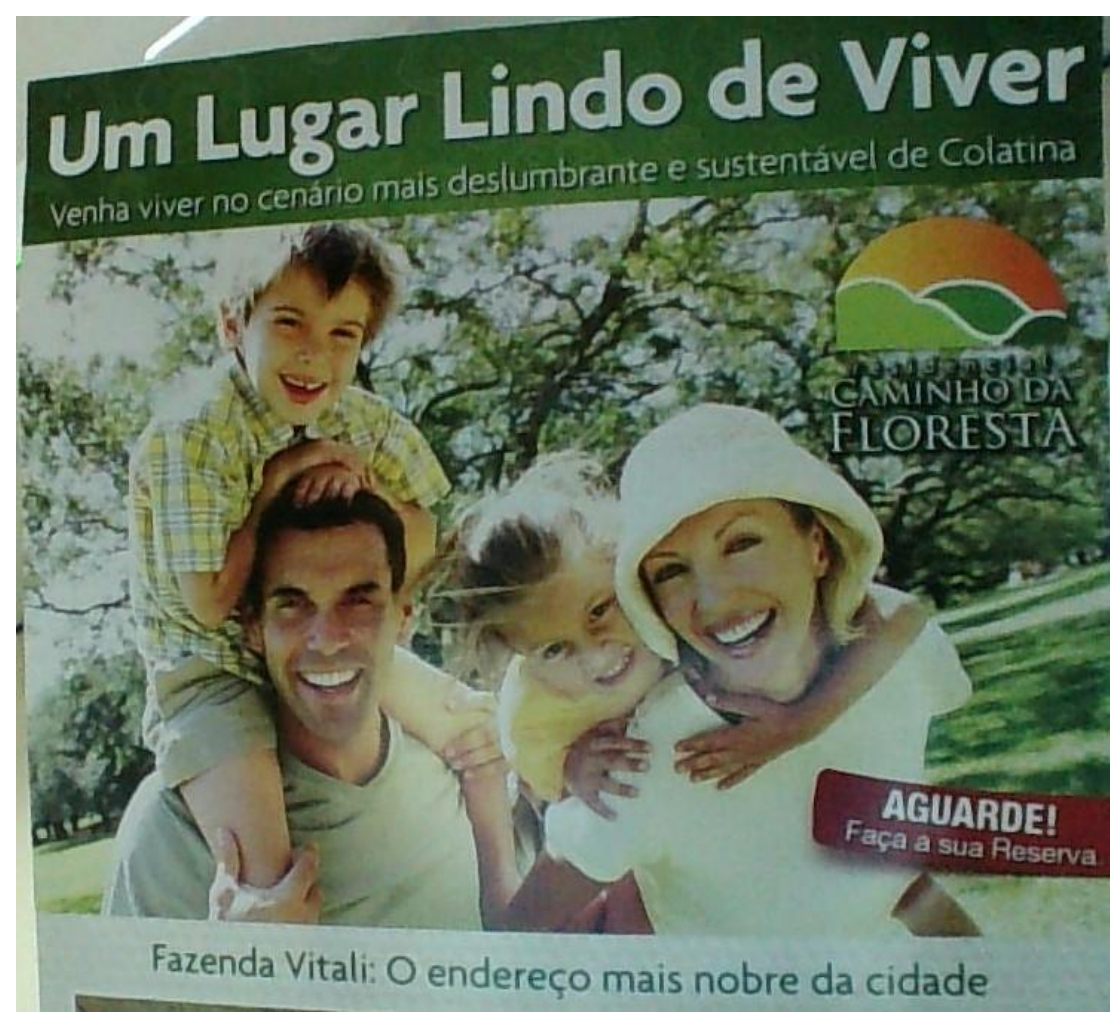

Fonte: folder publicitário do empreendimento. Engest Construtora, 2016. 
A proximidade com a natureza e a presença de ventilação natural também são utilizadas amplamente como forma de valorizar os lotes recém-urbanizados. Henri Lefebvre (2008) apontava que os elementos naturais como a água, o ar e a luz, por estarem ameaçados, seriam postos em pedaços, fragmentados e vendidos segundo os interesses do capital. Essa possibilidade de "vender" atributos naturais, exposta por Lefebvre (2008), expõe a qualidade da não reprodução destes itens, e que por essa razão as promove como fontes de constantes conflitos.

\section{SETORES EXTERNOS À PRODUÇÃO IMOBILIÁRIA EM COLATINA}

É pertinente relacionar a oferta de novos loteamentos às condições econômicas que possibilitaram a criação de um mercado consumidor para esses novos produtos. Dessa forma, será apresentado um breve resumo das mudanças ocorridas no período da pesquisa que podem relacionar-se como uma alteração das condições de mercado.

Da centralidade apresentada por Colatina na região centro-oeste do Espírito Santo ressalta-se que, na hierarquia das Regiões de Influência do Espírito Santo (IJSN, 2011), a cidade mantém vínculo direto com sete centros locais, ou seja, cidades cujas economias não extrapolam os limites dos próprios municípios. Os deslocamentos de pessoas em busca de atividades de comércio e serviços em Colatina são importantes para a caracterização do município enquanto polo. O mesmo possui ampla oferta de serviços de saúde - tem 262 estabelecimentos de atividades de atenção à saúde (RAIS/MTE, 2016) -, o que representa a maior quantidade oferecida por um município em toda a região norte do Espírito Santo.

Acerca dos serviços de saúde, novos equipamentos surgiram na cidade e outros foram desenvolvidos expressivamente no período analisado nesta pesquisa. Como referência de novo equipamento destaca-se o São Bernardo Apart Hospital, dotado com 140 leitos e diversas especialidades médicas e inaugurado em 2007, aumentando os serviços prestados na cidade (São Bernardo, 2016). Em 2008, o hospital UNIMED foi reinaugurado após ampla reforma e passou a oferecer 68 leitos e, também, diversas especialidades médicas.

O setor educacional corresponde também como fonte de atração de pessoas na região, pois possui dois campi do Instituto Federal do Espírito Santo, dois centros superiores de ensino 
e uma extensão da Universidade Federal do Espírito Santo. Essa oferta contribui para o afluxo da população dos municípios vizinhos à cidade de Colatina.

A indústria do vestuário de Colatina, importante historicamente para o município, também contribui para a migração positiva. Além do tradicional e movimentado comércio varejista do Centro da cidade, foi construído, em 2011, o maior shopping atacadista de vestuário do estado, que tem capacidade para 167 lojas de pronta-entrega e atende lojistas de diversos estados do país.

Além dos serviços de saúde e educação citados acima, a comercialização do café também deve ser indicada como relevante. Após o programa de erradicação dos cafezais, na década de 1960, o setor apresentou redução significativa na produção cafeeira do município, no entanto, ela foi retomada na década de 1970, sob novas bases produtivas que promoviam a aplicação de técnicas modernas no cultivo do café (CAMPOS JUNIOR, 2004). Com isso, podese afirmar que carências de serviços e particularidades dos municípios vizinhos possuem impactos nas demandas por atividades em Colatina. As alterações na dinâmica dos municípios vizinhos, grandes produtores de café e dos quais Colatina comercializa a produção, influenciam no mercado da cidade e também na demanda de novos lotes, para moradia ou investimento.

\section{CONSIDERAÇÕES FINAIS}

De acordo com as análises deste estudo, percebe-se que o mercado imobiliário apropriase de determinadas características da cidade, naturais e de localização. Das características naturais, citamos proximidade de áreas verdes, mesmo que escassas, o vento nos locais mais altos e a vista para o pôr do sol e para o rio Doce. De localização, o mercado imobiliário "vende" a proximidade aos serviços coletivos, dos quais Colatina é referência regional, principalmente de saúde, educação e o comércio varejista.

A apropriação das qualidades como forma de diferenciação dos lotes urbanos recémconstruídos cria condições para que o crescimento da área citadina ocorra de maneira acelerada. O pagamento de renda sob a forma de loteamentos contribui para que os proprietários fundiários reservem suas terras, criando uma falsa escassez, produzindo vazios e aumentando os custos de manutenção da cidade.

O que se pode confirmar acerca desse crescimento horizontal acelerado é que a cidade é produzida através da lógica de mercado. A compreensão das formas de utilização do solo, 
especialmente do “(...) movimento complexo pelo qual a cidade política utiliza o caráter sagrado-maldito do solo a fim de a cidade econômica (comercial) o profane” (LEFEBVRE, 2001: p. 73) é que se faz importante para a compreensão do processo.

\section{REFERÊNCIAS}

BRASIL. Ministério do Trabalho e Emprego - MTE. Relação anual de informações sociais RAIS. Brasília: disponível em: http://trabalho.gov.br/rais, acessado em novembro de 2016.

CAMPOS JÚNIOR, C. T. de. A formação da centralidade de Colatina. Vitória: IHGES, 2004.

COLATINA. Prefeitura Municipal. Parcelamento do solo urbano do município de Colatina. Lei Municipal $\mathrm{n}^{\circ} \quad 4.227 / 1996 . \quad$ Disponível em http://www.legislacaocompilada.com.br/colatina/Arquivo/Documents/legislacao/html/L42271 996.html, acessado em 5 de janeiro de 2016.

BOTTOMORE, T. Dicionário do pensamento marxista. Rio de Janeiro: Jorge Zahar, 2001.

HARVEY, D. Cidades Rebeldes: do direito à cidade à revolução urbana. São Paulo: Martins Fontes, 2014.

HARVEY, D. Los limites del capitalismo y la teoria marxista. Cidade do México: Fundo de Cultura Econômica, 1990.

HARVEY, D. Temas urbanos e regionais. o trabalho, o capital e o conflito de classes em torno do ambiente construído nas sociedades capitalistas avançadas. Disponível em: $<$ https://pt.scribd.com/document/.../TEXTO-Temas-Urbanos-e-Regionais-Harvey>, acessado em 30 de novembro de 2016.

INSTITUTO JONES DOS SANTOS NEVES (IJSN). Espírito Santo em mapas. Vitória, 2011. Disponível em: www.ijsn.es.gov.br, acessado em novembro 2015.

LEFEBVRE, H. Espaço e política. Belo Horizonte: Universtária/UFMG, 2008.

LEFEBVRE, H. O direito à cidade. São Paulo: Centauro, 2001.

MARX, K. O capital: crítica à economia política. $1^{\text {a }}$ Edição. Livro III: o processo global da produção capitalista; edição de Friedrich Engels. São Paulo: Boitempo, 2017.

PEREIRA, P. C. X. Espaço, técnica e construção. São Paulo: NOBEL, 1988.

SÃO BERNARDO. Grupo São Bernardo Saúde. Dados disponíveis em: <http://www.saobernardoaparthospital.com.br>, acessado em 21 de dezembro de 2016. 